\title{
SPECIES DISTRIBUTION OF ROADSIDE GRASSHOPPERS IN SOUTHERN SASKATCHEWAN
}

MICHAEL J. BIDOCHKA, Bioinsecticide Laboratory, Department of Applied Microbiology and Food Science, University of Saskatchewan, Saskatoon, Saskatchewan. S7N OW0

In the summer of 1985 grasshopper densities in southern Saskatchewan reached heights not previously recorded on agricultural land since 1935. The Estevan and Weyburn areas reported grasshopper nymph densities of approximately 500 individuals per square meter. The repercussions of such an outbreak were immediately felt by the farming community in southern Saskatchewan where some wheat farmers lost whole fields of wheat in the early stages of growth. Monetary losses due to the grasshopper infestation were in the order of 100 million dollars. The grasshopper pesticide, Malathion, had to be flown in from eastern U.S. cities by the R.A.F. since pesticide demand was greater than supply to suppress the grasshopper plague.
The grasshopper outbreaks of the 1930's in southern Saskatchewan were dominated by one particular species, the Migratory Grasshopper, Melanoplus sanguinipes and this species continues to be the single most devastating insect pest of the Canadian prairies.' Riegert also reported local infestations of the Clear-winged Grasshopper Camnula pellucida. Packard's Grasshopper, M. packardii, and the Two-striped Grasshopper, M. bivittatus, were of secondary importance, particularly in the southern regions.

On 15 June 1985 grasshoppers were sampled approximately $15 \mathrm{~km}$ southeast of Regina in an area predominated by wheat farming. Grasshoppers were collected by

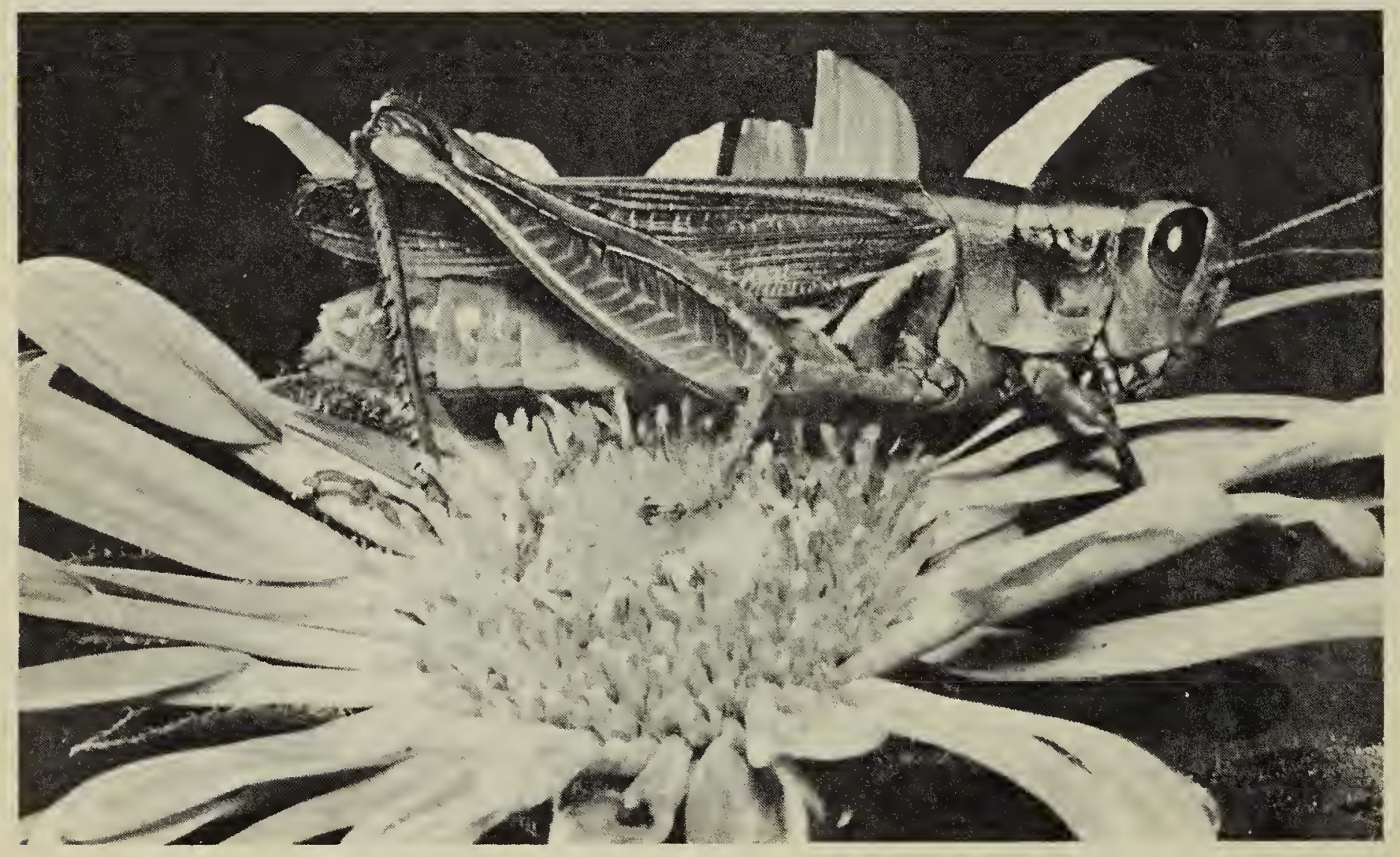


Table 1. SPECIES DISTRIBUTION, SEX RATIO AND TOTAL NUMBER OF NYMPHS FROM

A ROADSIDE SAMPLE OF GRASSHOPPERS NEAR REGINA, SASKATCHEWAN

Species

Melanoplus sanguinipes

M. packardii

Camnula pellucida

M. bivittatus

Aeropedellus clavatus

M. femurrubrum

$M$. infantilis

$M$. foedus

M. confusus

M. angustipennis

\begin{abstract}
Total \#
Adults
\end{abstract}

686

213

202

180

17

10

7

3

3

1
$\%$ of Total
Catch

51.89

16.11

15.28

13.62

1.29

0.75

0.53

0.22

0.22

0.07
Male/female

Ratio

1.95

3.63

1.43

2.05

1.83

0.43

1.33
Total \#

Nymphs

101

34

45

41

6

0

0

0

0

0 extending a net from the car $25 \mathrm{~cm}$ from the ground and driving $30 \mathrm{kmph}$ along the roadside. A total of 1322 individual adult grasshoppers were collected, frozen, identified to species and sexed. Nymphal grasshoppers were also identified to species.

Table 1 presents data from the 10 species collected. Over $50 \%$ of the total adult catch was the Migratory Grasshopper. This species, along with all members of the genus Melanoplus belongs to a classification known as spur-throated grasshoppers. If you pick up a grasshopper, turn it on its back and find a short, stubby spur between the front legs, it is probably a Melanoplus. The common species, the Migratory Grasshopper, is brownish-yellow and approximately 23-28 mm long. Their hind legs have a series of black bands and their tibia may be red or blue; red are predominant around the Yorkton area, blue are predominant in the southern areas of the province. Some species are difficult to key and positive identification relies on the size and shape of the terminal abdominal structures such as the cerci, subgenital and supraanal plate.

Packard's Grasshopper, the Clear-winged Grasshopper and the Two-striped Grasshopper were of secondary importance with a total combined catch of approximately $45 \%$. The roadside habitat also supported such non-economic species as $M$. infantilis, M. foedus, $M$. confusus, $M$. femurrubrum and the Club-horned Grasshopper, Aeropedellus clavatus.

In the economically important species, more males were caught than females. This figure may not represent a naturally occuring disproportionate sex ratio, but rather it may represent sexual differences in mobility (i.e jumping into the net when startled by the oncoming vehicle). Mobility differences may be a reflection of sexual differences in size (Table 2). Females were from 1.16 times larger in weight (M. sanguinipes) to 1.8 times larger than males (C. pellucida). Overall, the largest species was the Twostriped Grasshopper with females being 1.6 times larger in weight than males. Females, being generally larger, may not jump as quickly when startled or, may tend to hug the ground instead of jumping. Females have pointed abdominal ends used for egg laying and thus can be distinguished from males.

Grasshopper species composition and densities may be different between roadside and field conditions since most economic species tend to bask in the sun along roadside stubble. ${ }^{1}$ In any case, these data give valuable information on economic species distribution in a wheat-growing area of southern Saskatchewan. 
Table 2. WEIGHT OF ECONOMICALLY IMPORTANT MALE AND FEMALE GRASSHOPPERS

Species
M. sanguinipes
M. bivittatus
M. packardii
C. pellucida

Males
Weight $(m g)$

20

20

20

20

$\begin{array}{lr}289.62 & 46.11 \\ 496.74 & 105.19 \\ 434.011 & 85.08 \\ 178.733 & 29.89\end{array}$

Females

S.D. * Weight (mg) S.D. *

336.95

81.72

792.85

221.84

590.19

178.85

325.30

* $N$ sample size number; S.D. standard deviation

I RIEGERT, P.W. 1968 A history of grasshopper abundance surveys and forecasts of out- breaks in Saskatchewan. Memoirs of the Entomological Society of Canada No. 52

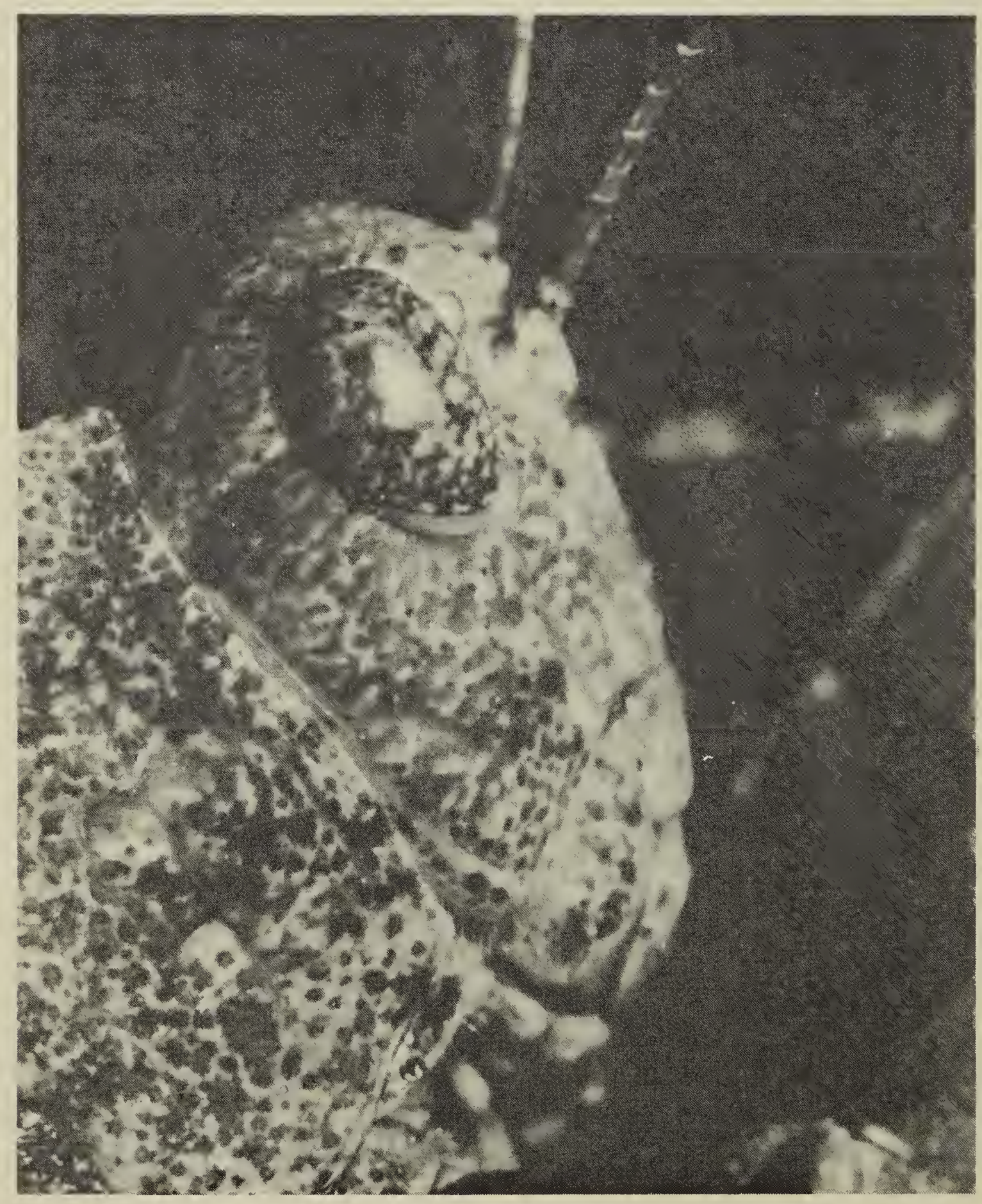

